\title{
Evolution of Electronic Approval Request Procedures at Charlotte Douglas International Airport
}

\author{
Lindsay Stevens \\ NASA Ames Research Center \\ Moffett Field, CA, USA \\ lindsay.stevens@,nasa.gov
}

\author{
Todd J. Callantine \\ San Jose State University at NASA Ames \\ Moffett Field, CA, USA \\ todd.callantine@nasa.gov
}

\author{
Robert Staudenmeier \\ Cavan Solutions \\ Frederick, MD, USA \\ bob.staudenmeier@cavansolutions.com
}

\begin{abstract}
At many major U.S. airports, a departure approval request, or 'APREQ,' establishes a later runway departure time for a flight, allowing it to absorb tactical delay on the ground. APREQ times are traditionally coordinated by a process known as 'call-for-release' whereby an airport surface traffic manager calls an airspace traffic manager on the telephone. This research examines new electronic APREQ coordination enabled by the NASA Airspace Technology Demonstration-2 system and compares it to the call-for-release method of coordination. During the initial deployment period, electronic APREQ coordination was used for more than half of eligible flights. A majority of electronic requests were approved in less than one minute on average. Data suggest that both the average tactical delay and compliance with the electronically coordinated departure times did not differ significantly from departure times coordinated using call-forrelease.
\end{abstract}

Keywords-APREQ, electronic coordination

$$
\text { call-for-release, }
$$

procedures,

\section{INTRODUCTION}

The NASA Airspace Technology Demonstration-2 (ATD-2) project seeks to develop and demonstrate an integrated arrival, departure, and surface (IADS) traffic management capability in collaboration with the FAA, the National Air Traffic Controllers Association, and industry partners $[1,2]$. The initial deployment phase of ATD-2 is focused on efficiency, predictability, and throughput improvements in airport surface and departure operations enabled by data integration and sharing, surface movement scheduling, and tactical departure scheduling. The ATD-2 system became operational at Charlotte Douglas International Airport (CLT) in September 2017. ATD-2 seeks to incrementally refine fielded IADS capabilities to support 'metroplex' operations via continued stakeholder engagement and supporting research through 2020.

FAA IADS concepts for system-wide traffic-flow management hinge on three decision-support systems: the Time Based Flow Management (TBFM) system, the Traffic Flow Management System (TFMS), and the Terminal Flight Data Manager (TFDM). TBFM performs time-based scheduling, TFMS helps manage airspace and surface resource utilization, and TFDM will handle electronic flight data exchange and integration. A key goal of ATD-2 is to demonstrate the potential of future IADS operations by bridging gaps between these evolving systems and supporting data flows to enable air traffic controllers and airspace users to exercise envisioned capabilities. Data and user feedback obtained during ATD-2 will prove invaluable for system-wide implementation of IADS concepts in the future.

One focus area concerns linking Traffic Management Initiatives (TMIs) developed and disseminated via TFMS to TBFM scheduling capabilities. TMIs are aimed at addressing demand-capacity imbalances, and include ground delay programs, ground stops, required re-routes, miles-in-trail restrictions, and departure approval requests ('APREQs') [3]. This paper focuses on APREQ restrictions, traditionally handled by an Air Traffic Control (ATC) Tower traffic manager calling an Air Route Traffic Control Center ('Center') traffic manager on the telephone to request a runway departure time (or 'release time') for an aircraft that plans to transit the Center's airspacea process known as 'call-for-release.' APREQs are an important tool through which Centers can efficiently apply tactical delay to aircraft still on the ground, reducing airborne delay-vectoring and controller workload by ensuring that space is available for aircraft in congested sectors or traffic streams.

There has been a significant amount of historical work done to develop automated APREQ scheduling assistance tools. The evolution of these tools began with NASA's Departure Release Calculator [4,5]. Metron then leveraged work from the FAA and Surface Collaborative Decision Making (S-CDM) groups to develop the Departure Reservoir Management prototype, which monitored airport demand/capacity balance and provided strategic surface scheduling [6]. NASA's Precision Departure Release Capability $[1,7,8]$ allowed ATC Towers to coordinate release times with the Center. This was a precursor to the FAA's Integrated Departure Arrival Capability (IDAC) within TBFM. IDAC is designed to support departure demand monitoring and slot identification [9]. IDAC also streamlines the APREQ process by augmenting call-for-release procedures with semiautomatic and automatic modes for requesting release times from ATC Towers equipped with the Integrated Departure Scheduling Tool (IDST). In November 2017, CLT ATC Tower traffic managers began using an electronic APREQ coordination feature in the ATD-2 system, similar to the FAA's IDST, to electronically negotiate APREQ times for flights to the U.S. northeast via a connection to TBFM/IDAC at Washington Center (ZDC). This paper describes the electronic negotiation procedures and presents initial findings concerning use of the semi-automatic APREQ negotiation mode.

The paper first provides background on TMIs at CLT and call-for-release procedures. It then describes electronic APREQ negotiation procedures and the ATD-2 system. After presenting 
results from the initial implementation period, the paper discusses implications and the evolution of APREQ negotiation in later phases of ATD-2 deployment.

\section{BACKGROUND}

CLT is a primary hub for American Airlines, situated in Atlanta Center (ZTL) near the boundaries of Washington and Jacksonville Centers, beneath busy traffic flows to the northeast. CLT experiences significant surface congestion during peak operations and is frequently subject to TMIs. In general, TMIs are classified as strategic or tactical based on scope and the level of the initiating authority. The most prevalent TMIs at CLT are strategic Expect Departure Clearance Times (EDCTs) and tactical TMIs implemented as APREQs and/or miles-in-trail restrictions.

EDCTs are runway departure times imposed by the Air Traffic Control System Command Center to address broad demand-capacity imbalances across the National Airspace System. A flight subject to an EDCT is expected to depart the runway within five minutes before or after the specified time. Tactical TMIs such as APREQs, on the other hand, are intended to relieve congestion at specific fixes or meter points. Tactical TMIs are more locally focused, usually involving coordination between terminal area and/or ATC Tower traffic managers with traffic managers in their 'home' Center. Today, APREQs and miles-in-trail restrictions are usually implemented and monitored with the aid of TBFM, which is configured with timebased schedules at the relevant fixes or meter points. Like most airports, CLT ATC Tower coordinates with its home Center (i.e., ZTL) in implementing APREQs for westbound traffic (the largest percent to Atlanta). A unique aspect of CLT ATC Tower is that it also coordinates directly with ZDC to implement TMIs for traffic bound to airports within the Washington D.C. and New York metroplexes. It is more efficient for ZDC to schedule CLT traffic directly into the core TMI rather than having ZTL schedule flights into a secondary TMI before passing the flights to ZDC. This also reduces the burden of additional traffic on ZTL.

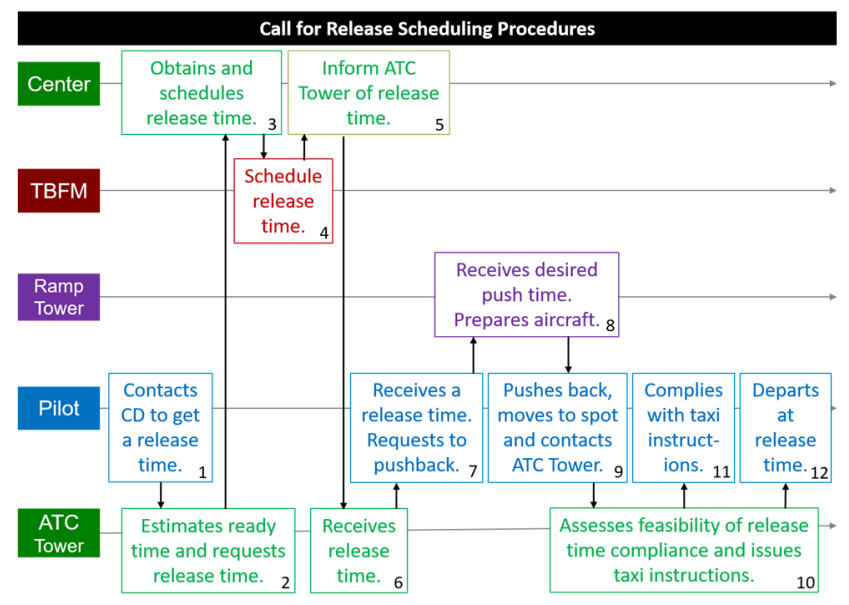

Fig. 1. Diagram of call-for-release procedures showing steps for call-forrelease from pilot ready to aircraft departing the runway.

Call-for-release procedures (Fig. 1) have traditionally been used to negotiate release times for flights with APREQ restrictions. Pilots contact the ATC Tower Clearance Delivery position prior to pushback to obtain their pre-departure clearance. If the flight is subject to an APREQ restriction, pilots are advised to call back at pushback to receive their APREQ release time. When the pilot calls at pushback, the ATC Tower traffic manager calls the Center traffic manager to request a release time, supplying the time at which the flight is projected to be ready to depart from the runway. The Center traffic manager enters the projected runway departure time in TBFM, assesses the availability of a slot at the meter point, and communicates a release time for the flight that Clearance Delivery then relays to the pilot. Aircraft are expected to depart no more than two minutes before or one minute after the approved release time.

The call-for-release procedure, using land-line communication between ATC Tower and Center, is highly inefficient and time-consuming. Traffic managers at ZDC, for example, may receive requests from up to fourteen ATC Towers, each with multiple destination requests. Before approving each release time, traffic managers must ensure a slot is available on the TBFM schedule timeline for the particular meter point a flight plans to cross. Arrival-departure banks prevalent in hub-based operations are likely to precipitate many calls in the same timeframe. It is possible that CLT ATC Tower may need to wait more than three minutes for ZDC to respond. APREQ coordination delays may in turn be transferred to departing aircraft.

\section{ELECTRONIC APREQ COORDINATION IN ATD-2}

The ATD-2 system consists of client displays and tools in the ATC Tower and in the ramp tower that exchange data via a data-fusion and mediation component that also integrates TBFM, TFMS, TFDM, TMI, surface surveillance, and airlineprovided data. ATC Tower personnel use the ATD-2 Surface Trajectory-Based Operations (STBO) Client (Fig. 2); ramp tower personnel use the ATD-2 Ramp Traffic Console (RTC). In addition to integrating IADS information about TMIs, arriving aircraft, and airline surface operations, the ATD-2 architecture includes a channel that supports the protocol for exchanging information between TBFM/IDAC and IDST required for electronic APREQ coordination (Fig. 3). ATC Tower traffic managers can request release times through the

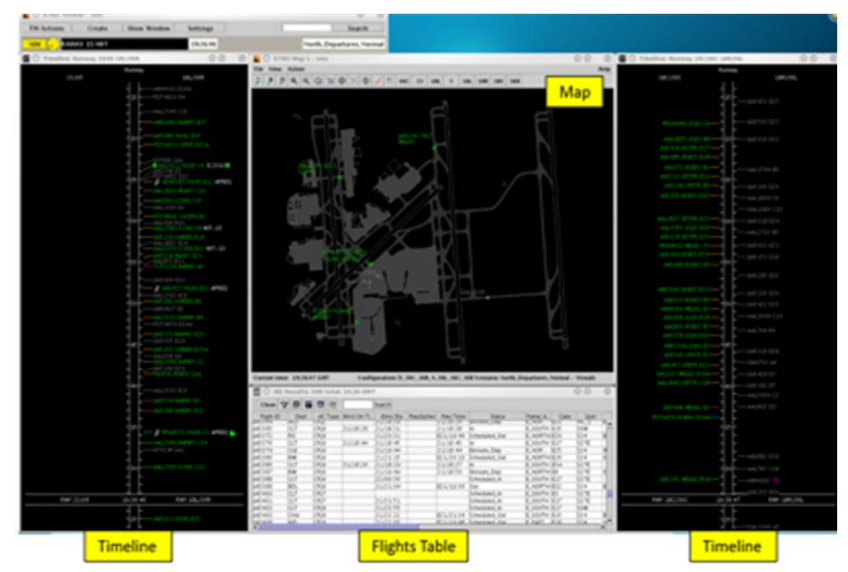

Fig. 2. STBO Client interface, showing the toolbar, map, flights table, and timeline features. 


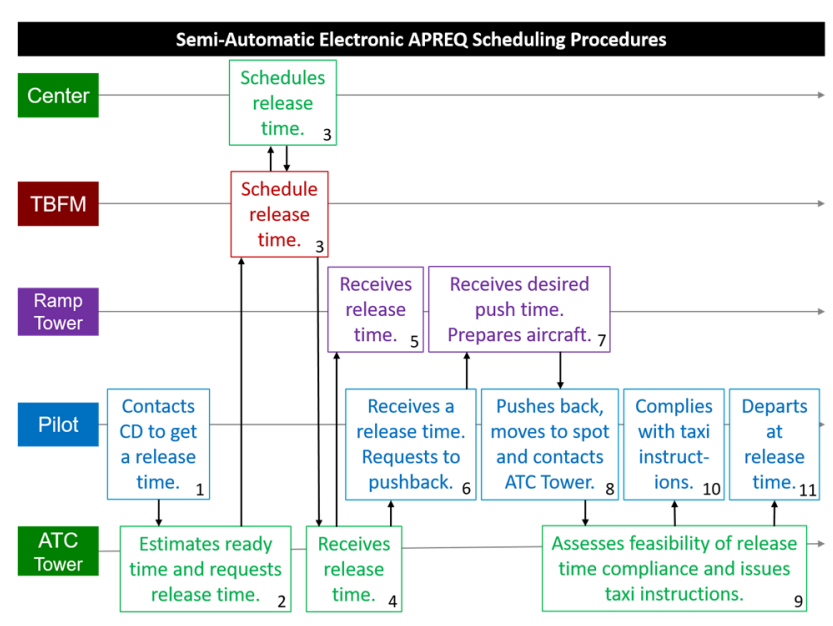

Fig. 3. Diagram of electronic APREQ coordination procedures showing steps for electronic APREQ coordination from pilot ready to initial process to aircraft departing the runway.

STBO Client, and Center traffic managers can use TBFM to electronically transmit approved release times back to STBO.

The integration of IDST capabilities in the STBO Client improves the ATC Tower's awareness about available slots in the overhead traffic flow. Under electronic coordination, when the ATC Tower selects an APREQ flight on the timeline, red line and green block spaces are depicted in the center of the timeline (Fig. 4). Red line spaces indicate times for which TBFM predicts the overhead flow is occupied, whereas green block spaces indicate times when slots are available. This information was not previously available; under call-for-release, the ATC Tower could not predict what the release time provided by the Center might be. The STBO Client further enhances IDST capabilities by reflecting the runway demand, including arrivals, on the timeline, enabling the ATC Tower to request release times in accordance with other surface traffic management considerations. Furthermore, the STBO Client enables the ATC Tower to assess progress toward meeting the release time, reassess slot availability, and potentially renegotiate a release time for the aircraft. The following subsections describe the electronic APREQ coordination process in detail.

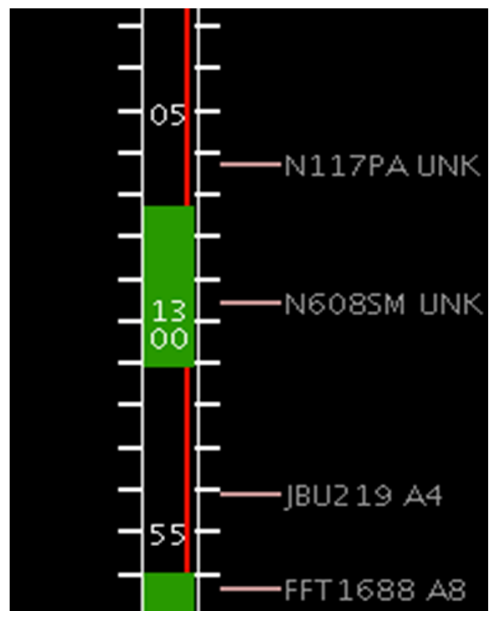

Fig. 4. STBO Client timeline overhead stream slot availability for APREQ flights. (Green: available slots; Red: unavailable slots)

\section{A. Enabling Electronic Coordination}

Electronic coordination of APREQ release times begins at the Center. A settings panel within TBFM/IDAC (Fig. 5) enables the Center, first, to activate electronic APREQ coordination at specific airport ATC Towers. Second, the Center can specify the mode for approving requests for release times that come from a specific ATC Tower. The Center can choose between three modes: call-for-release, semi-automatic, and automatic. The semi-automatic and automatic modes allow for electronic APREQ coordination, whereas the traditional callfor-release mode requires Center-ATC Tower land-line communication to coordinate release times. Finally, the Center can configure TBFM to send back the accepted time based on various cues.

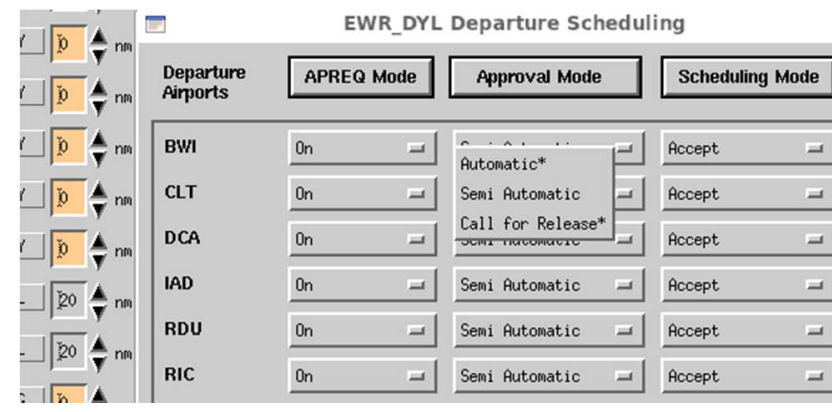

Fig. 5. Setting Center approval modes for APREQ release time requests in TBFM.

The Center TBFM configuration for a given ATC Tower is reflected on that ATC Tower's STBO Client timelines via symbols displayed next to the call-signs of flights subject to APREQs, as shown in Fig. 6. A telephone handset symbolizes that the Center requires call-for-release, whereas unfilled and filled lightning bolts symbolize the availability of semiautomatic and automatic coordination modes, respectively.

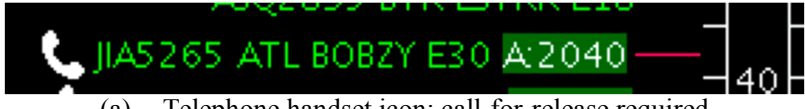

(a) Telephone handset icon; call-for-release required

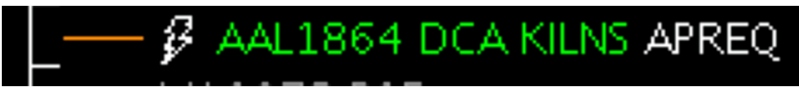

(b) Unfilled lightning-bolt icon; semi-automatic mode available

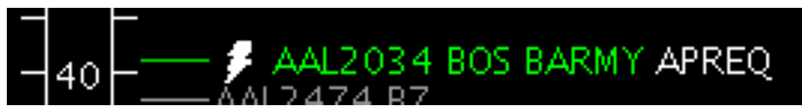

(c) Filled lightning-bolt icon; automatic mode available

Fig. 6. STBO Client timeline display of available APREQ coordination methods.

\section{B. Call-for-Release Mode}

The Center may elect to use the call-for-release mode due to TBFM/IDAC system limitations where electronic negotiation is not supported, such as when an APREQ aircraft is being scheduled into a TBFM system two Centers away. Call-forrelease is also required during system outages. 


\section{Semi-Automatic Mode}

Semi-automatic mode provides the significant advantage of freeing the ATC Tower and Center from land-line communications, creating time to attend to other duties. Semiautomatic mode also affords the Center flexibility in assigning release times. For example, although the STBO Client timeline indicates a slot is available at a particular time, the Center may approve a later release time in cases where sector overloading is anticipated. The Center may also approve a later release time to coincide with the termination of airborne holding for a destination so the released aircraft fits smoothly into the overhead flow without experiencing an airborne holding delay. Semi-automatic mode also keeps the Center informed regarding responses to ATC Tower APREQ requests, enhancing situation awareness. During the study period for this paper, ZDC exclusively used semi-automatic mode for electronic APREQ coordination.

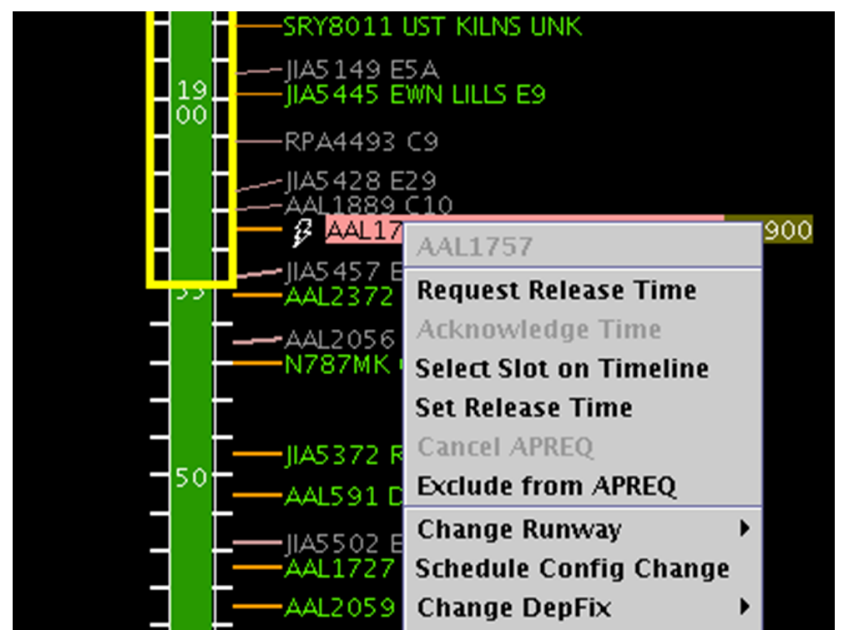

Fig. 7. Context menu on STBO Client timeline for APREQ flights.

For aircraft that the STBO Client indicates are eligible for semi-automatic coordination (Fig. 6b), the ATC Tower has two options for electronically requesting a release time from the Center. Both are accessed by right-clicking the flight's data tag on the STBO Client timeline to display a context menu (Fig. 7). The 'Request Release Time' option directs STBO to automatically choose an available slot relative to the aircraft's expected time to reach the runway, and electronically send the requested time to the Center TBFM/IDAC. If the ATC Tower desires greater control over the requested time, the 'Select Slot on Timeline' option may be selected. The ATC Tower may then left-click within the 'red/green' area of the timeline to choose a specific requested time to electronically send to the Center. Once either option is invoked, a yellow arrow is displayed to the right of the flight's data tag to indicate STBO has sent the requested time to the Center (Fig. 8).

\section{(A5 149 E5A}

\section{AAL1757 EWR KLLNS B15 APREQ E:1900 $\rightarrow$}

Fig. 8. Yellow arrow on STBO Client timeline indicating APREQ release time request has been sent.
At the Center, TBFM/IDAC produces an audible tone to indicate that it has received an electronic request for an APREQ release time from an ATC Tower. It also highlights the flight's call-sign in pink on its TBFM timeline and displays a yellow diamond-shaped alert symbol next to it, so that the Center traffic manager can easily identify it (Fig. 9). If desired, the Center can modify the ATC Tower's requested time by dragging the callsign up or down the timeline. Clicking the diamond or accessing a context-menu item sends the approved time back to the ATC Tower.

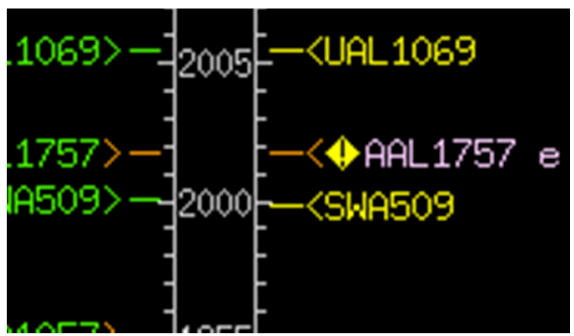

Fig. 9. APREQ release-time request received on TBFM timeline. (Pink call-sign with alert)

When the STBO Client receives the approved time, it changes the timeline indication for the affected flight. If the Center approved the originally requested release time, the STBO Client replaces 'APREQ' with the letter 'A' followed by the four-digit time (Fig. 10). If the approved time differs from the originally requested time, the STBO Client emits an audible tone and replaces 'APREQ' with the approved time, plus a yellow diamond-shaped alert symbol (Fig. 11). The ATC Tower traffic manager can acknowledge the new time and clear the alert symbol by left-clicking the diamond or selecting 'Acknowledge Time' from the flight's context menu.

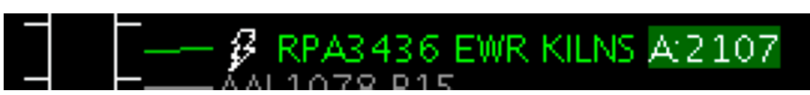

Fig. 10. STBO Client timeline display of approved APREQ release time.

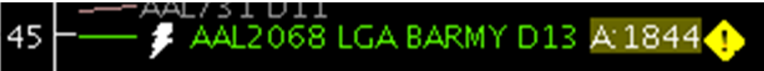

Fig. 11. STBO Client timeline display of approved APREQ release time different from orignally requested time.

The STBO Client also includes the ability to request a specific APREQ release time by manually entering the time. The ATC Tower may access this method, which is available during all possible verbal and electronic methods of APREQ coordination, via the 'Set Release Time' context-menu item (Fig. 7).

\section{Automatic Mode}

In the automatic APREQ coordination mode, the ATC Tower follows the same procedures to request a release time for a flight as described above for the semi-automatic mode. However, TBFM/IDAC determines a release time and sends the approved time back to STBO without any action required from the Center user. The automatic mode is not currently in use in the CLT ATD-2 deployment, but could eventually enter use during periods when the Center feels comfortable that sector- 
overloading or other factors are not a problem, and that APREQ compliance is meeting expectations.

\section{E. APREQ Compliance}

Flights with APREQ release times are expected to depart the runway within a compliance window from two minutes earlier to one minute later than the release time. From the moment an APREQ release time is scheduled for a flight, STBO calculates the flight's ability to comply with the release time and colorcodes the release time on the STBO Client timeline to alert the ATC Tower of its projected release-time compliance (Fig. 12). Green highlighting indicates the flight is projected to comply with its assigned release time (Fig. 12a). Mustard-yellow highlighting indicates the aircraft is projected to depart the runway early (Fig. 12b), whereas red highlighting indicates the aircraft is projected to depart late (Fig. 12c). If the ATC Tower determines action is required to comply with the release time, they may opt to adjust the aircraft or reschedule the release time. When the aircraft reaches the Airport Movement Area (AMA) where control is transferred from ramp to ATC, STBO

\section{F ASQ5456 LGA BARMY A9 A 1835}

(a) Green highlighting; projected to depart on time

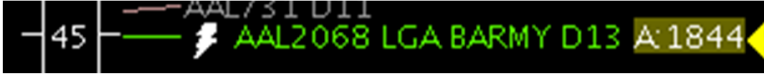

(b) Mustard-yellow highlighting; projected to depart early

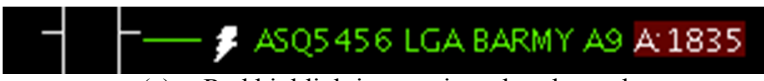

(c) Red highlighting; projected to depart late

Fig. 12. STBO Client timeline indicators of projected APREQ compliance.

reevaluates the flight's projected compliance estimate considering the overall departure queue. This approach has the potential to remove unnecessary delay by enabling the ATC Tower to identify earlier available slots and modifying release times accordingly.

\section{F. Removing APREQs}

The dynamic nature of operations with TMIs at times makes it desirable to adjust the requirements on APREQs for specific flights. At CLT, in particular, APREQ restrictions imposed by ZDC typically remain in force for long periods. At times when larger gaps are present in the scheduled ZDC traffic flows, it may not be necessary to assign a release time to all flights that are normally subject to APREQs, or a flight that has been assigned an APREQ may end up not requiring it (e.g., when a flight needs priority handling, or must return to the gate to address a maintenance issue). In these cases, the ATC Tower may select 'Exclude from APREQ' or 'Cancel APREQ,' respectively, from the flight's STBO Client timeline context menu (Fig. 7).

\section{G. Data Exchange}

One of the ATD-2 system's benefit mechanisms is the ability of STBO in the ATC Tower to exchange data with RTC in the ramp tower. In addition to reducing the possibility of voicecommunication errors, STBO-RTC data exchange gives the ramp controllers access to a variety of previously unavailable data. For example, with the introduction of the ATD-2 system at CLT, ramp controllers are now aware of both APREQ restrictions and approved APREQ release times (Fig. 13). This allows ramp controllers to prompt pilots of flights that have APREQ restrictions, but are missing release times, to contact Clearance Delivery, promoting a more streamlined transition across the airport surface. Aircraft may also absorb some of the delay created by an APREQ restriction at their gates, reducing fuel-burn, emissions, and ramp congestion. RTC also provides push-back clearance advisories to assist the ramp controllers in ensuring aircraft reach the runway in time to comply with their release times.
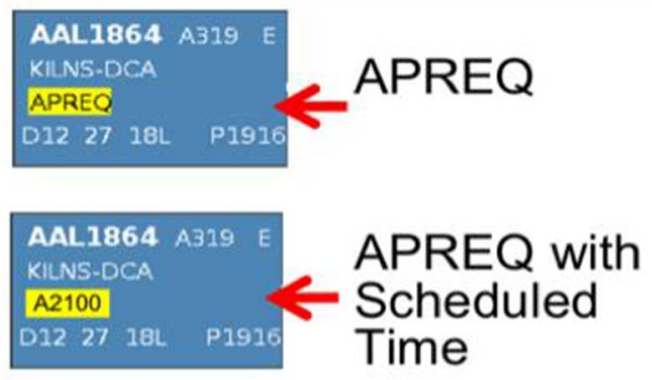

Fig. 13. Flight strip on RTC. (top: APREQ restriction without a scheduled release time; bottom: scheduled APREQ release time)

\section{H. ATD-2 APREQ Procedures Evolution at CLT}

In 2017, NASA conducted a human-in-the-loop simulation to evaluate the ATD-2 technologies prior to their deployment to the CLT operational environment [10]. Feedback from CLT ATC Tower personnel who participated in the simulation at NASA Ames Research Center resulted in modifications to the STBO interface. Among the changes reflected in the above description was the removal of a timeline indication that a flight was within ten minutes of pushing back from the gate and ready for an APREQ release time. The simulation results also supported adding the capability to exclude individual flights from an APREQ restriction, adding audible alerts when the approved time differs from the requested time, and changing the acknowledgement requirements for release times received from the Center to apply only to release times that varied from the originally requested times.

The ATD-2 system was deployed for operational use at CLT in September 2017. Since that time, the system has undergone incremental updates and improvements. Initially, call-forrelease procedures for negotiating APREQ release times remained in use; however, ATD-2 tools also displayed release times to users after the verbal coordination was complete. Electronic APREQ negotiation with TBFM/IDAC at ZDC was enabled at CLT through the ATD-2 system in November 2017, allowing CLT ATC Tower to begin engaging in semi-automatic release time coordination for many flights to the northeast. Due to no current IDAC connection with ZTL, all flights subject to ZTL APREQs continue to be coordinated via call-for-release procedures. The next section of the paper presents results on the initial use of electronic APREQ coordination procedures in semi-automatic mode. 


\section{INITIAL DEPLOYMENT RESULTS}

Data on APREQ negotiation were collected from the ATD2 system fielded at CLT for a 41-day period from 23 November 2017 to 2 January 2018. The data consist of electronically logged data, augmented by manual coding of screen-capture video from the operational system to examine user interaction with the interface. The data include 27,479 CLT departures with 2,561 (9.3\%) subject to APREQ restrictions, 659 (2.4\%) subject to EDCTs, and 355 (1.3\%) departures subject to both APREQ and EDCT restrictions. The principal video-coded data elements of interest are the method of semi-automatic APREQ coordination employed, the times at which release times were requested, and the times at which approved release times populated on the STBO timelines.

The availability of analyzable screen-capture videos yielded a set of 38 analyzable days, covering 2,274 APREQ flights that comprise $8.3 \%$ of total CLT departures during the study period. CLT ATC Tower negotiated 1,400 (61.6\%) of these with ZDC and $874(31.4 \%)$ with ZTL.

\section{A. Use of Electronic APREQ Coordination}

Only ZDC has the capability to coordinate APREQs electronically with CLT, and only then for flights to the Washington D.C. metroplex. Of the 1,400 ZDC APREQs, 1,054 (75.3\%) occurred when TBFM/IDAC was available and configured for electronic coordination per Fig. 5 above; for 103 (7.4\%), IDAC was available but not configured for electronic coordination (Fig. 14).

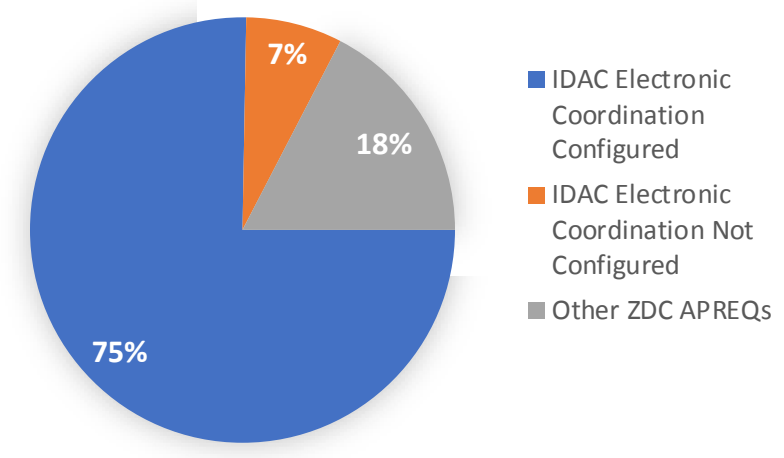

Fig. 14. Proportion of ZDC APREQs eligible for electronic coordination.

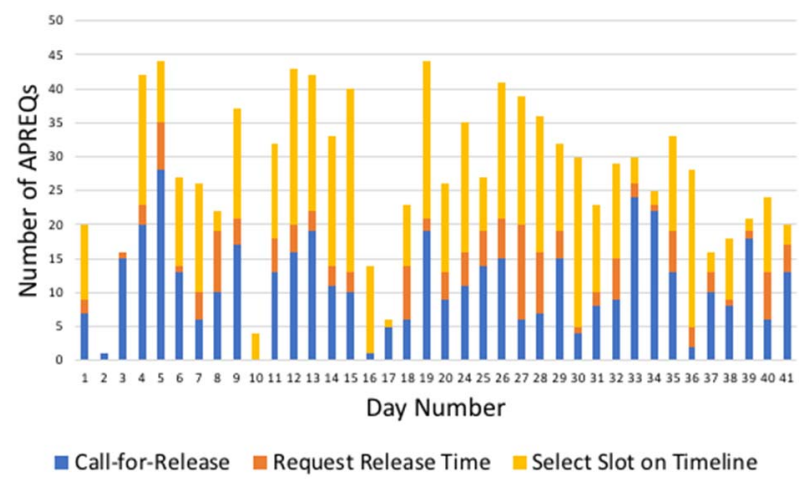

Fig. 15. Initial electronic APREQ coordination methods used per day on for flights eligible for electronic coordination.
For ZDC APREQs with electronic coordination available, Fig. 15 shows the number of release times initially requested with call-for-release, 'Request Release Time,' and 'Select Slot on Timeline' for each day in the study period. Overall, 618 $(58.9 \%)$ of APREQs were coordinated electronically out of 1,049 (excluding one requested using 'Set Release Time' and four with the precise request method unknown) that were eligible to be coordinated electronically. On $74 \%$ of days, electronic coordination was used more than call-for-release. Across all days, 'Select Slot on Timeline' was used more than three times as often as 'Request Release Time'. No effect of time passage on the proportion of release times scheduled with 'Select Slot on Timeline' vs. 'Request Release Time' was observed (Fig. 16); however, the ATC Tower continued to use the 'Request Release Time' method throughout the study period.

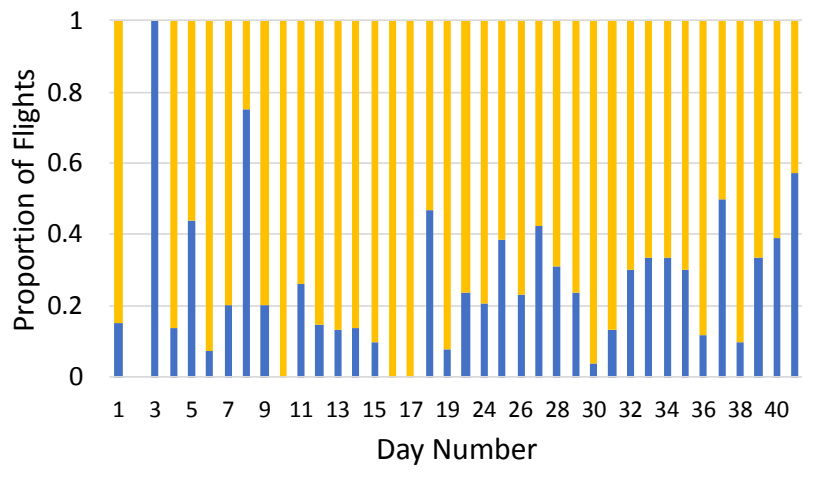

Request Release Time Select Slot on Timeline

Fig. 16. Request method as a proportion of electronically coordinated APREQs.

\section{B. APREQ Rescheduling}

Of the full set of 2,274 APREQ flights, the ATC Tower requested to reschedule release times for 478 flights $(21 \%)$, for an average of $12.5(\mathrm{SD}=6.1)$ flights per day. The ATC Tower requested multiple release time reschedules for 129 flights $(5.7 \%)$, with the twelfth and thirteenth days of the study period accounting for 41 of these multiply-rescheduled flights. For the 478 APREQ flights with rescheduled release times, an average of 20.2 ( $\mathrm{SD}=22.1)$ mins elapsed between when the ATC Tower received the first approved release time and the last.

Video-coded data are available for 437 flights with rescheduled release times. Table I provides the breakdown of the number of flights for each of the pairings of initial release time coordination method by the rescheduled release time coordination method. Call-for-release was used as the reschedule method for a majority of the flights. This result was expected, given that the STBO Client's electronic reschedule capabilities were never trained to users at that time.

TABLE I. COORDINATION METHODS FOR RESCHEDULED RELEASE TIMES By INITIAL SCHEDULING METHOD

\begin{tabular}{|c|c|c|c|}
\hline \multirow{2}{*}{$\begin{array}{c}\text { Initial Scheduling } \\
\text { Method }\end{array}$} & \multicolumn{3}{|c|}{ Rescheduling Method } \\
\cline { 2 - 4 } & $\begin{array}{c}\text { Select Slot on } \\
\text { Timeline }\end{array}$ & $\begin{array}{c}\text { Request } \\
\text { Release Time }\end{array}$ & $\begin{array}{c}\text { Call-for- } \\
\text { Release }\end{array}$ \\
\hline $\begin{array}{l}\text { Select Slot on } \\
\text { Timeline }\end{array}$ & 33 & 0 & 65 \\
\hline
\end{tabular}




\begin{tabular}{|l|c|c|c|}
\hline \multirow{2}{*}{$\begin{array}{c}\text { Initial Scheduling } \\
\text { Method }\end{array}$} & \multicolumn{3}{|c|}{ Rescheduling Method } \\
\cline { 2 - 4 } & $\begin{array}{c}\text { Select Slot on } \\
\text { Timeline }\end{array}$ & $\begin{array}{c}\text { Request } \\
\text { Release Time }\end{array}$ & $\begin{array}{c}\text { Call-for- } \\
\text { Release }\end{array}$ \\
\hline $\begin{array}{l}\text { Request Release } \\
\text { Time }\end{array}$ & 2 & 2 & 20 \\
\hline Call-for-Release & 8 & 0 & 307 \\
\hline
\end{tabular}

\section{APREQ Aircraft Location}

Digital data that specify a 'surface flight state' internal to the ATD-2 system are available for 1,933 of the 2,274 APREQ flights (Table II). Fig. 17 shows the known states for all initial APREQs across the study period by day. These data show that the release time requests were completed before pushback for $64.3 \%$ of flights and completed during pushback for $17.5 \%$ of flights. Only $18.2 \%$ of the total flights had the initial release time scheduled after the push-back procedure was complete. It is typical CLT procedure to begin the coordination for the APREQ release time when the flight calls the ATC Tower Clearance Delivery prior to push-back. The data demonstrate that this procedure was consistently utilized during the study period.

TABLE II. Summary OF FLIGHT States ON INITIAL REQUEST

\begin{tabular}{|l|c|c|}
\hline \multicolumn{1}{|c|}{ Flight State } & Number of Flights & Percentage \\
\hline At Gate & 1,243 & 64.3 \\
\hline During Pushback & 339 & 17.5 \\
\hline Taxiing in Ramp & 133 & 6.9 \\
\hline Taxiing in AMA & 142 & 7.4 \\
\hline In Runway Departure Queue & 76 & 3.9 \\
\hline
\end{tabular}

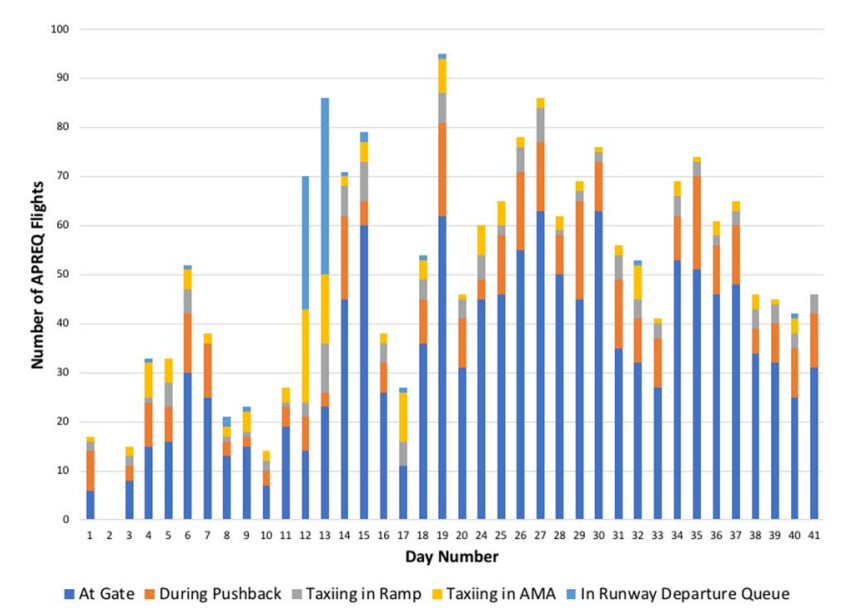

Fig. 17. APREQ flight state on initial release-time request by day.

By contrast, for the 457 of 478 APREQ flights with rescheduled release times and surface flight states available, the ATC Tower completed the last release-time-reschedule request for only $14.2 \%$ of flights before push-back and only $10.9 \%$ while aircraft were pushing back from the gate (Table III). The remaining $74.8 \%$ of flights had final release-time-reschedule requests completed while aircraft were moving across the airport surface (Fig. 18). Rescheduling of release times typically is a result of a tactical need to request a new time due to a flight's inability to meet the originally requested time or due to the aircraft arriving, or being projected to arrive, at the runway early. Aircraft without a controlled time will often taxi out before or behind their scheduled departure time, thus changing the runway time for the controlled aircraft. Events leading to these reschedules typically unfold while the aircraft is taxiing to the runway, resulting in nearly three quarters of these reschedules occurring while the aircraft was moving. Only $17.1 \%$ were rescheduled while the aircraft was in the runway departure queue, which suggests that for a majority of the flights that were rescheduled, the ATC Tower had enough information available to be aware of the need for the reschedule prior to the aircraft reaching the runway.

TABLE III. Summary Of Flight States On Rescheduling

\begin{tabular}{|l|c|c|}
\hline \multicolumn{1}{|c|}{ Flight State } & Number of Flights & Percentage \\
\hline At Gate & 65 & 14.2 \\
\hline During Pushback & 50 & 10.9 \\
\hline Taxing in Ramp & 87 & 19.0 \\
\hline Taxiing in AMA & 177 & 38.7 \\
\hline In Runway Departure Queue & 78 & 17.1 \\
\hline
\end{tabular}

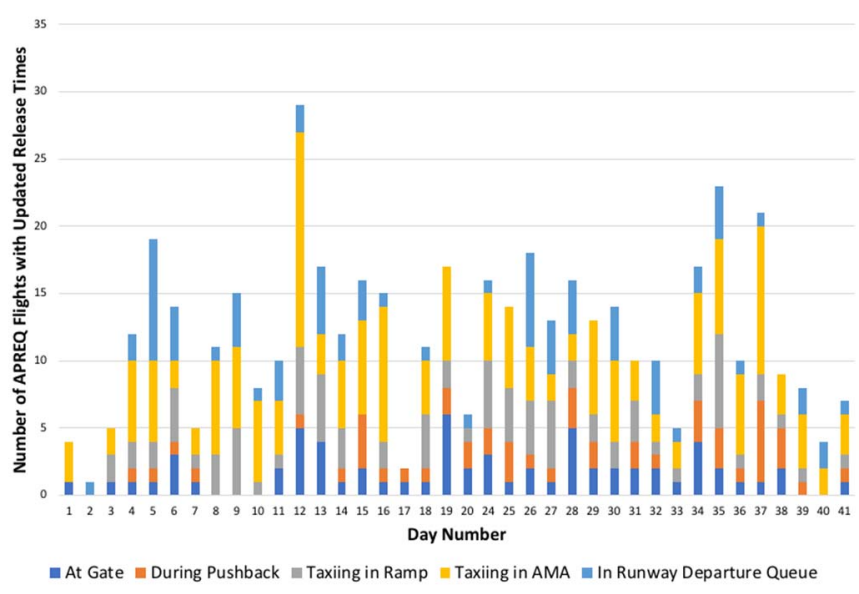

Fig 18. APREQ flight state on final-update release-time request by day.

For APREQ flights that the ATC Tower coordinated electronically with ZDC, 556 had 'surface flight state' data available. The ATC Tower initially used 'Select Slot on Timeline' to request a release time for 426 (76.7\%) flights (Fig. $19 a)$ and 'Request Release Time' to make 130 (23.3\%) requests (Fig. 19b). The ATC Tower completed a similar proportion of release time requests for the 'Select Slot on Timeline' and 'Request Release Time' during all stages of the departure process - from coordination at the gate to in the runway departure queue. 


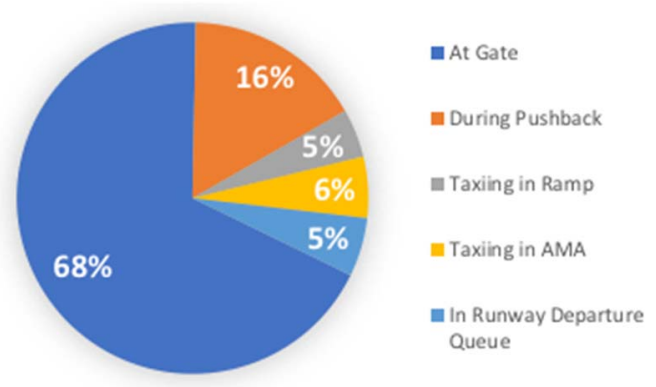

(a) Select Slot on Timeline

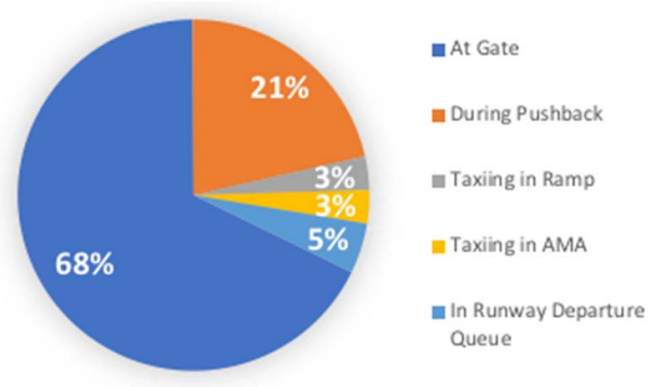

(b) Request Release Time

Fig. 19. Initial electronic coordination request locations by request method.

\section{Response Times}

Electronic coordination response times were calculated from the moment the ATC Tower entered requests into the STBO Client to the moment the STBO Client timelines displayed the Center's approval responses. Valid video-coded approval response times are available for 607 electronically coordinated APREQs (98.2\%). The mean time for a Center-approved release time to populate the STBO Client timelines was $36 \mathrm{sec}(\mathrm{SD}=40$ $\mathrm{sec}$ ) for initial APREQ requests made using 'Request Release Time', and $43 \mathrm{sec}(\mathrm{SD}=89 \mathrm{sec})$ for initial requests using 'Select

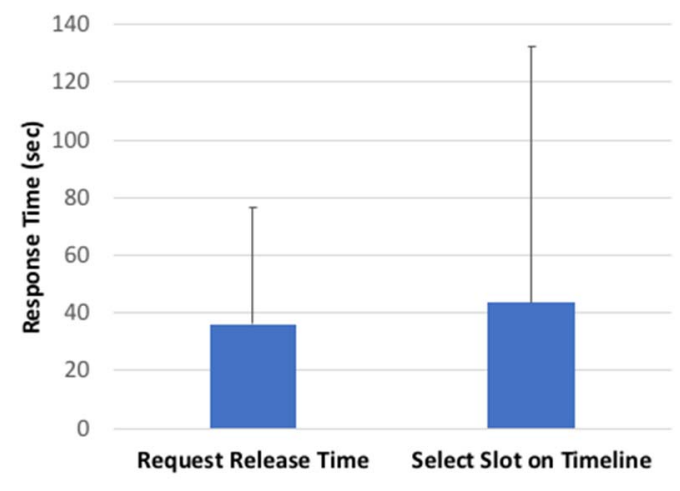

Fig. 20. Average response times in seconds for initial APREQ requests by method. (Error bars indicate one standard deviation)

Slot on Timeline' (Fig. 20). In addition, Fig. 21 shows that for both methods, the average time for the ATC Tower to receive an approved release time from the Center on any day rarely exceeded one minute.

\section{E. APREQ Delay}

Digital data were available for the final APREQ release time that was scheduled for each flight, referred to as the 'Final APREQ Time'. Digital data were also available for the expected departure time, or 'Ltime'. The amount of delay that gets added by an APREQ restriction on a flight is the difference between the 'Final APREQ Time' and the 'Ltime' (Eq. 1). Flights whose final APREQ time was scheduled using call-for-release received an average of $24.4 \mathrm{~min}(\mathrm{SD}=16.6 \mathrm{~min}$ ) of added delay (Fig. 22). Flights whose final APREQ time was scheduled using 'Request Release Time' received an average of $26.6 \mathrm{~min}(\mathrm{SD}=10.3 \mathrm{~min})$ of added delay. Flights whose final APREQ time was scheduled using 'Select Slot on Timeline' received an average of $26.1 \mathrm{~min}$ $(\mathrm{SD}=13.7 \mathrm{~min})$ of added delay.

$$
\text { APREQ delay }=\text { Final APREQ Time }- \text { Ltime }
$$

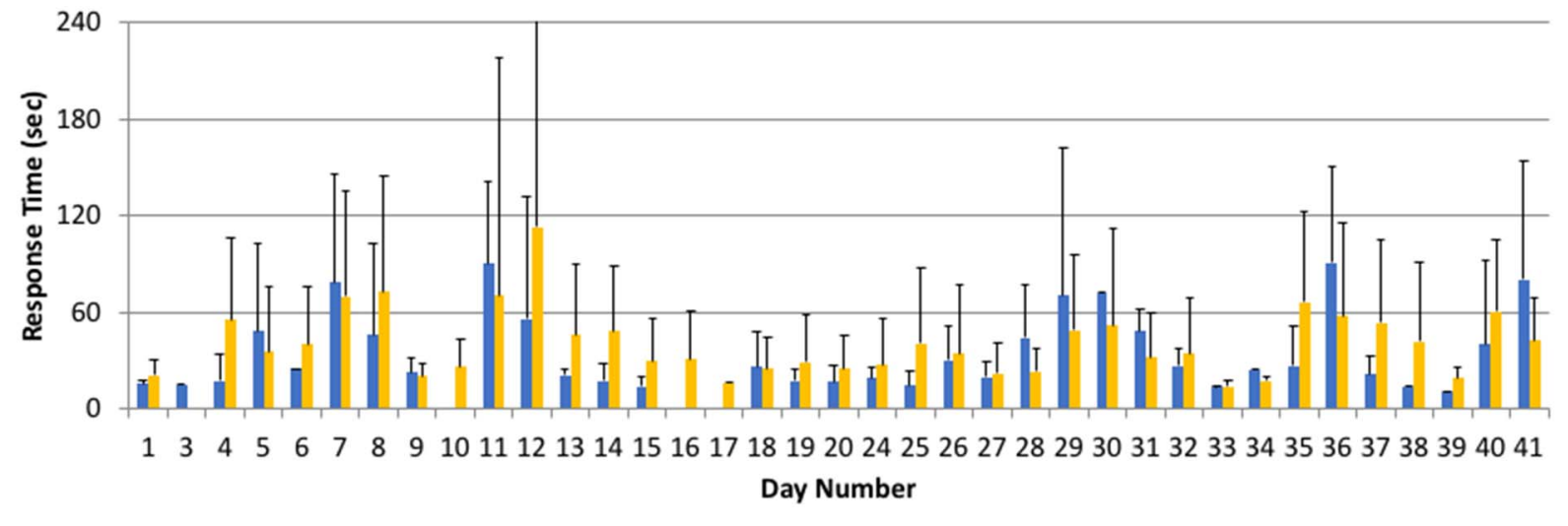

Request Release Time $\quad$ Select Slot on Timeline

Fig. 21. Average response time in seconds for initial APREQ requests by method per day. (Error bars indicate one standard deviation) 


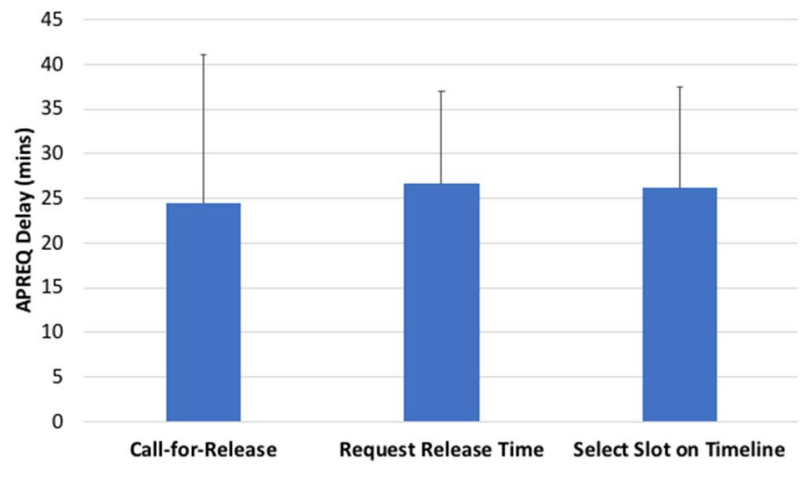

Fig. 22. Average delay (in minutes) added to flights with APREQ release times. (Error bars indicate one standard deviation)

\section{F. APREQ Compliance}

Digital data for actual time of runway departure and the final APREQ release time scheduled were available for all flights. APREQ compliance was calculated by applying a four-minute window to the APREQ release time (two minutes ahead to one minute behind the scheduled APREQ release time, including the release time itself) and assigning a binary value of 'met window' or 'did not meet window'. Fig. 23 shows that flights scheduled using call-for-release complied with the APREQ release time $61.7 \%$ of the time; $68.8 \%$ of flights scheduled with the 'Request Release Time' method complied with the APREQ release time; and $58.0 \%$ of flights scheduled using 'Select Slot on Timeline' complied with the APREQ release time.

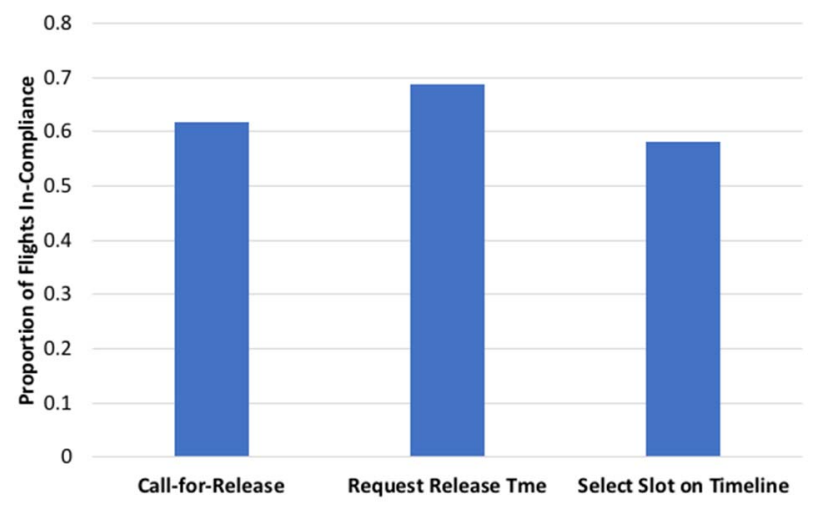

Fig. 23. APREQ compliance by release time scheduling method.

For the study period, 270 flights that had both APREQ and EDCT restrictions were video-coded. Fig. 24 shows that, for flights with release times scheduled using call-for-release, $63.4 \%$ complied with the APREQ release time. For flights electronically coordinated using 'Request Release Time' and 'Select Slot on Timeline', 58.3\% and $60.7 \%$ complied with the APREQ release time window, respectively.

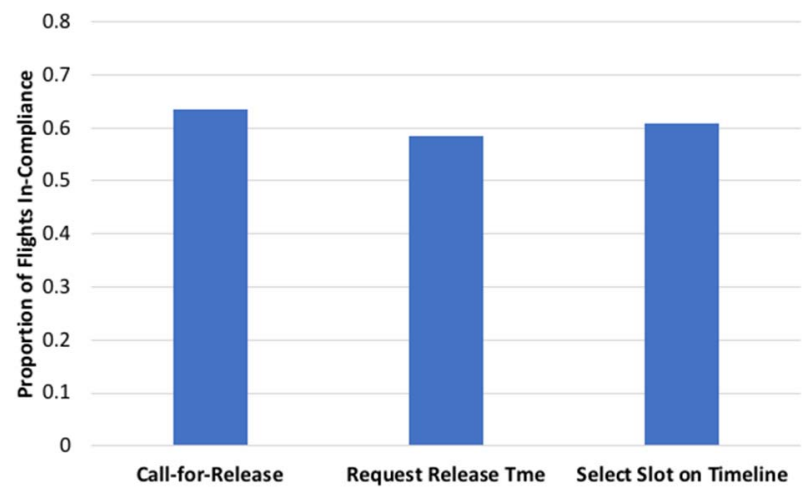

Fig. 24. APREQ compliance by release time scheduling method for APREQ flights that also have an EDCT restriction.

APREQ compliance for both flights with and without an additional EDCT restriction are comparable between the callfor-release and electronic APREQ coordination procedures, with slightly better compliance for APREQ-only flights when scheduled with 'Request Release Time'. There are a number of difficulties experienced by the ATC Tower with respect to achieving APREQ compliance. At CLT, the layout of the airport introduces some complexities that are not shared by many other top-ten U.S. airports. In particular, there is no 'hammerhead' at CLT - an area at the end of a runway that provides space to hold an aircraft. Hammerheads are helpful for enabling aircraft to depart at a specific time. Additional challenges stem from dualuse runways at CLT. This means that the ATC Tower must wait for a space between arrival traffic to release a departure, which may interfere with APREQ compliance by seconds. Other challenges imposed by the integration of arrival and departure traffic on a single runway include the amount of time an arrival spends taxiing off a runway and potential losses of slots due to tightened spacing on final approach for arrivals. Each time a gap in the arrival spacing is missed for releasing a departure, additional delays are incurred. This also results in CLT experiencing long runway queues.

\section{DISCUSSION}

The ATD-2 project seeks to augment operations through improved data integration and sharing, while providing performance on-par or better than current-day tools and procedures. The results presented here hold promise for achieving this goal. During the 41-day study period, over half of all flights eligible for electronic coordination of APREQ release times were indeed coordinated using electronic methods. Although 'Select Slot on Timeline' was used typically three times more often as 'Request Release Time', continued engagement with the more automated 'Request Release Time' feature by ATC Tower traffic managers was encouraging. ATC Tower traffic manager self-reports reflect a desire for control in scheduling release times, so allowing the system to choose the release time using 'Request Release Time' is a welcome demonstration of willingness to engage with the new technology.

It was peculiar to discover that ATC Tower traffic managers rescheduled APREQ release times using electronic coordination 
because, while the ATD-2 system supported it, this feature was never advertised or trained. The low number of rescheduling attempts using electronic coordination may reflect this lack of information. ATC Tower users continue to find innovative ways of engaging with the ATD-2 technology as new features are incrementally deployed.

For both methods of electronically coordinating APREQ release times, the average time for the ATC Tower to receive an approved release time from the Center on any day rarely exceeded one minute. Due to the congestion of call-for-release requests from multiple ATC Towers at the Center, an ATC Tower could spend between three and seven minutes completing the release time coordination process for a flight verbally, so electronic APREQ coordination stands to make significant time available for users to address other tasks. Although responsetime data are not available for the call-for-release APREQs, experienced Center and ATC Tower traffic managers serving as ATD-2 subject matter experts stated that electronic coordination provides a substantial response-time reduction.

No statistical difference was found in the amount of additional delay incurred by APREQ flights based on release time request method. Similar findings were reported for APREQ compliance. For electronic APREQ coordination and associated ATD-2 system performance results reported here, performance with the ATD-2 system met or exceeded current-day operations.

\section{A. Future Direction}

Procedures for electronic coordination of APREQ release times have continued to evolve at CLT ATC Tower since the capability was enabled in November 2017. Further changes began on 3 January 2018, one day after the study period of this paper. New features and continual improvements for the APREQ electronic negotiation continue to be added to the STBO Client. Future research will examine more streamlined concepts such as fully-automated electronic coordination of release times and the capability to electronically swap release times for two APREQ flights subject to the same APREQ restriction. Other capabilities, such as STBO automatically probing TBFM for opportunities for the ATC Tower to electronically reschedule better release times for flights, are also anticipated. Moreover, it is expected that STBO will be able to exchange information with electronic flight strips used by ATC Tower ground and local controllers to guide traffic, which may provide more precise information to predict flight surface trajectories and runway departure times. Future research will analyze the impacts of such enhancements on delay reduction, APREQ compliance, fuel-burn, emissions, and other metrics.

\section{REFERENCES}

[1] Y. Jung, et al., "Airspace Technology Demonstration 2 (ATD-2) Phase 1 Concept of Use (ConUse)," NASA/TM-2018-29770, February, 2018.

[2] Federal Aviation Administration, "NextGen Priorities Joint Implementation Plan., https://www.faa.gov/nextgen/media/NG_Priorities_Joint_Implementatio n_Plan.pdf, accessed 27 June, 2018.

[3] J. Rios, "Aggregate statistics of traffic management initiatives," 10th AIAA Aviation Technology, Integration, and Operations Conference, Fort Worth, TX, 13-15, 2010.

[4] P. Kopardekar, S. Green, C. Brinkman, P. Thompson, M. Evans, and D. Davis, "Making Internal Departure Release Operations More Efficient," AIAA 2004-6346, $4^{\text {th }}$ AIAA Aircraft Technology, Integration, and Operations (ATIO) Forum, 2004.

[5] P. Kopardekar, S. Green, and P. Thompson, "Improving Efficiency of Departure Release Communications for En Route Overhead Traffic Flow Management," $23^{\text {rd }}$ Digital Avionics Systems Conference (DASC), 2014.

[6] Surface CDM Team, US Airport Surface Collaborative Decision Making (CDM) Concept of Operations (ConOps) in the Near-Term: Application of Surface CDM at United States Airports, 2012.

[7] A. Capps, E. Walenciak, \& S. Engelland, Impact of Departure Prediction Uncertainty on Tactical Departure Scheduling System Performance. $12^{\text {th }}$ AIAA Aviation Technology, Integration, and Operations (ATIO) Conference and $14^{\text {th }}$ AIAA/ISSMO Multidisciplinary Analysis and Optimization Conference, 2012.

[8] S. Engelland, A. Capps, K. Day, M. Kistler, F. Gaither, and G. Juro, "Precision Departure Release Capability (PDRC) Final Report," NASA/TM-2013-216533, 2013.

[9] E. Chevalley, B. Parke, J. Kraut, N. Bienert, and F. Omar, "Scheduling and Delivering Aircraft to Departure Fixes in the NY Metroplex with Controller-Managed Spacing Tools," 15th AIAA ATIO Conference, 2015.

[10] L. Stevens, L. Martin, K. Jobe, B. Parke, E. Chevalley, et al., "Evaluation of Approval Request/Call for Release Procedures for Charlotte Douglas International Airport”. 36 ${ }^{\text {th }}$ DASC, 2017. 